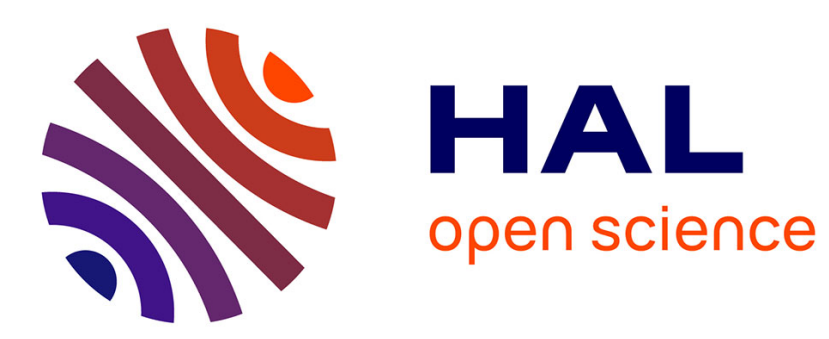

\title{
Ports in a world maritime system: a multilevel analysis \\ César Ducruet
}

\section{To cite this version:}

César Ducruet. Ports in a world maritime system: a multilevel analysis. Céline Rozenblat, Guy Melançon. Methods for multilevel analysis and visualisation of geographical networks, Springer, pp.121-140, 2013, Methodos Series 11. halshs-00842079

\section{HAL Id: halshs-00842079 \\ https://shs.hal.science/halshs-00842079}

Submitted on 29 Sep 2014

HAL is a multi-disciplinary open access archive for the deposit and dissemination of scientific research documents, whether they are published or not. The documents may come from teaching and research institutions in France or abroad, or from public or private research centers.
L'archive ouverte pluridisciplinaire HAL, est destinée au dépôt et à la diffusion de documents scientifiques de niveau recherche, publiés ou non, émanant des établissements d'enseignement et de recherche français ou étrangers, des laboratoires publics ou privés. 


\title{
Ports in a world maritime system: a multilevel analysis
}

\author{
César Ducruet ${ }^{1}$
}

\begin{abstract}
Pre-final version of the chapter published in C. Rozenblat \& G. Melançon (eds.) (2013) Methods for Multilevel Analysis and Visualisation of Geographical Networks, Springer, Methodos Series 11, pp. 121-140.
\end{abstract}

\begin{abstract}
This chapter proposes an analysis of worldwide inter-port shipping flows from a strength clustering perspective. A diversity of factors seems to explain the formation of clusters: geographic proximity among closely located ports (i.e. maritime regions), trade proximity (corridors) and historical path-dependency (long-term ties) among more distant ports. Since those factors are not directly tested, this chapter paves the way for further research on the geographic and economic relevance of clusters in the network analysis of shipping flows.
\end{abstract}

Keywords: container shipping; globalization; maritime networks; port systems; strength clustering

\section{INTRODUCTION}

Contemporary sea transport carries about $90 \%$ of world trade volumes. Despite this enormous importance, very little attention has been paid to the spatial organization of maritime networks throughout transport geography. More likely are extensive works on air transport and other land-based networks; in the latter, of chief concern is the urban centrality, whereas seaports are often considered aberrant cases and of peripheral interest due to a dominantly continental conception of urban and economic geography.

\footnotetext{
${ }^{1}$ Researcher; Centre National de la Recherche Scientifique (CNRS), Université de Paris I Panthéon-Sorbonne, UMR 8504 Géographie-cités / Equipe P.A.R.I.S., 13 rue du Four, F-75006 Paris, France. Tel. +33 (0)140-464007 / Fax +33(0)140-464-009 / Email: ducruet@parisgeo.cnrs.fr
} 
This chapter aims at understanding further the relative position of seaports within a world maritime system formed by the circulation of containerships. A global database of daily vessel movements allows for elaborating individual network attributes of seaports. Such study shall bring some new light about the relation with classical indicators of throughput volume. Besides, this research wishes to apply clustering methodologies to the world graph in order to reveal functional regions in which ports are embedded, while evaluating the respective importance of geographical proximity and economical linkages.

The remainders of the chapter are organized as follows. A first section recalls the lack of network analysis on maritime networks throughout port geography and economics. It also provides some possible explanation about such lacks, together with key directions for potential improvements. The second section introduces the data and the methodology, together with some preliminary results with port rankings and a visualization of the world graph in 1996 and 2006. Based on the former, the third section provides a multilevel analysis through the application of strength clustering. Further research and implications for policy are announced in the conclusion.

\section{THE NETWORK ANALYSIS OF MARITIME TRANSPORT}

\subsection{A lack of network analysis on maritime transport}

Transport geographers have been victims of many obstacles challenging the study of maritime networks. One first obstacle is contextual. Recent technological revolutions in the maritime world that displaced port functions from urban areas have eroded the importance of maritime transport in public representations. While this has probably reinforced the influence of the central place theory as mentioned by Bird (1970), it has paradoxically renewed scholars' interest about the transformation of sea transport itself, notably through its impact on port development (Slack, 1993). Shipping networks have become more footloose, partly due to shrinking transport costs and reduced trade barriers in general (Clark et al., 2004), and to the capacity of shipping lines reorganizing their networks globally with increased bargaining power integrating land transport through vertical integration (Robinson, 2002). However, the spatial complexity reached by such changes worldwide seems to have discouraged scholars from mapping the new organization of sea transport. Instead, port and maritime specialists have concentrated their efforts on changes occurring within ports (Slack and Frémont, 2005), 
between ports of a given region (Ducruet et al., 2009), and across port hinterlands (Notteboom and Rodrigue, 2005), where various actors intervene in a territorial context that is more visible than across the oceans. In addition, containerisation has allowed for the integration of maritime transport with land-based logistics through the action of giant companies (Robinson, 2002), while the land leg has remained the most expensive part and has concentrated most efforts. Therefore, dynamics taking place across maritime space between ports are not wellknown, although current evolutions lead us toward an "ultimate system of maritime transportation [...] whereby every port node can theoretically be linked to every other port node" (Bird, 1984, p. 26).

A second obstacle is economical and technical. Detailed data on maritime traffic between ports is often difficult to obtain due to its rarity and its very high cost. Thus, most port and maritime specialists use aggregated measures of port throughput for comparative analysis (e.g. traffic volume, growth, and concentration), as a simplified and easily accessible measure to analyze indirectly spatial changes in sea transport, such as the impact of port selection and hub-and-spoke strategies of ocean carriers ${ }^{2}$. Some researchers have used data from meteorological offices to obtain a snapshot of the worldwide location of sea-going vessels (Brocard et al., 1995), while others encoded and computed manually paper-based sources recapitulating sequences of port calls by vessel and company (Joly, 1999). More recent research has used more easily accessible data derived from Containerisation International Yearbooks published annually. It provides information on the regular services of the world's main shipping lines, allowing the mapping of their geographical coverage by port or by region measured in Weekly Containerized Transport Capacity (Frémont and Soppé, 2005). However, the lack of available software other than classic Geographical Information Systems (GIS) prevented any innovation in the visualization and analysis of large maritime networks.

In a context of continuous growth, increased spatial complexity, and widening power of global alliances and shipping lines around the world, the usage of new visualization and analytical tools becomes necessary. However, such effort shall not ignore the specificities of maritime transport with regard to other transport networks.

\subsection{The specificities of maritime transport}

\footnotetext{
${ }^{2}$ See Lee et al. (2008) for a review of port development models and Ducruet et al. (2009) for a synthesis on port concentration studies
} 
Despite the rapid success of air transport for commercial use since its global spread, maritime transport has kept a very important role supporting, and even enhancing, globalization (Frémont, 2005). From the 1960s onwards, containerisation has facilitated the regional and global integration of transport and value chains (Robinson, 2002). Of course, this has been made possible in a context of lowering trade barriers and geopolitical stabilization after decolonization of the then-Third World, and collapse of the socialist block, resulting in high freedom of circulation, low transport costs, and continuous growth. Even the Soviet Union increased its domestic share of maritime transport from $2 \%$ to $9 \%$, not only for geopolitical purpose (e.g. supporting distant brother countries such as Cuba), but also for enlarging its commercial power as a response to Western imperialism (Vigarié, 1995).

Such evolutions have given shipping lines the liberty to invest heavily in new technologies: the regular and dramatic increase in vessel sizes is a proof of their success, reflected in the enormous literature on this subject throughout maritime and port studies. One key aspect of global transportation by sea is the evolution from trade support (demand-driven) to trade stimulation (offer-driven). It means that shipping lines have become proactive by providing efficient door-to-door services across oceans on ever longer distances, but also across continents, through the integration of terminal and logistics operations, notwithstanding the role of shippers, forwarders, and intermodal operators in ensuring the space-time continuum of freight flows (Ducruet and Van der Horst, 2009).

For ports, implications are enormous and varied. Ports are bound to waterside locations where physical conditions are increasingly important due to growing vessel size (e.g. 14-15 meters of maximal quay depth are required for large containerships). In addition, the technological revolution in sea transport (i.e. containerisation) has provoked a drastic selection of ports capable of planning new terminals equipped with modern - and costly - cargo handling facilities (Slack, 1985). Given the aforementioned freedom of circulation, shipping networks that have become increasingly footloose, selecting ports based on various factors such as centrality and intermediacy (Fleming and Hayuth, 1994). Centrality refers to the landward situation of the port with regard to hinterlands, markets, and intermodal arrangements, while intermediacy corresponds to the seaward situation facilitating the implementation of hub-andspoke strategies towards other ports. Such dynamics have fostered competition among neighbouring ports, resulting in traffic concentration at few load centres and hub ports, and 
traffic dispersion due to diseconomies of scale and the preference of ocean carriers for brand new facilities created on greenfield sites (Slack, 1999).

Thus, our traditional conception of port development processes has radically changed in the last few decades (Olivier and Slack, 2006). While ports and supply chains are "terminalized" by ocean carriers and terminal operators acquiring global portfolios (Slack, 2007), the factors of port growth or decline seem to have shifted in the hands of shipping lines. No longer is the proximity to a market or densely occupied hinterland sufficient to explain the distribution of traffic along a maritime range, although it is clear that despite a few exceptions of terminals built in the "desert" for transhipment purposes, most of the world's container traffic concentrates within large urban agglomerations, and this trend is actually increasing (Ducruet, $2008 \mathrm{a})^{3}$. For instance, Europe's largest container ports tend to locate as close as possible from the megalopolis ranging from London to Milan; the north European range being a perfect example of port concentration nearby Europe's core economic region (i.e. Rhine). Nevertheless, the maritime component of port evolution has gained an unprecedented importance. It is the focus of this chapter to find new ways measuring and comparing this importance worldwide.

\subsection{Possible improvements}

\subsubsection{Functions and performance of seaports}

Two main approaches in the literature on ports and maritime transport are essential to the understanding on how ports are positioned in shipping networks. The first approach is concerned by the geographical functions of ports. Depending on the quality of their insertion in maritime networks, container ports can be defined as global pivots, load centres, regional ports and minor ports (De Langen et al., 2002; Bichou and Gray, 2005). Such typology is rarely verified empirically due to the complexity of liner networks. As explained by De Langen et al. (2002), four main factors contribute to this complexity: the continuous increase in traffic volumes, the increase in the number of ports connected, the increase in vessel size, and the increase in the spatial freedom of ocean carriers. However as the authors argue, "the

\footnotetext{
${ }^{3}$ Ducruet (2008) calculated that the proportion of world container traffic at ports located in urban areas of over one million inhabitants has increased from $66 \%$ in 1980 to $77 \%$ in 2005 . Of course, this share is influence by the inclusion of many hub ports for which transhipment traffic is counted twice, such as in Singapore, Hong Kong, and Busan.
} 
role of different ports in maritime networks has not been documented, nor has a precise typology that would allow for such a precise exercise been proposed" (De Langen et al., 2002, p. 3).

More likely is the indirect analysis of port's insertion in maritime networks through empirical case studies. For instance, there have been studies on the distribution of seaborne connections of Australian, United Kingdom, and French ports on various scales (Britton, 1965; Bird, 1969; Von Schirach-Szmigiel, 1973). This has been complemented by the analysis of the number of vessel calls as a proxy for maritime performance in the United States (Lago et al., 2001 cited in De Langen et al., 2002) and worldwide, combined with other port and urban indicators (Ducruet, 2008a). As mentioned earlier, relevant data sources and analytical tools are lacking for measuring more complex realities based on large maritime networks.

In fact, the relative situation of ports within a given maritime system is analysed either theoretically, through the definition of hub functions, centrality, and intermediacy (Fleming and Hayuth, 1994; Fleming, 2000), the formulation of port concentration models within a port system, or empirically by the analysis of traffic distribution and concentration verifying such issues (Ducruet et al., 2009). However, the latter are based on aggregated individual measures (e.g. port throughputs), which hide to what extent ports handling similar traffic may, in fact, be very different in terms of seaborne connections and position in the networks, in terms of vulnerability. One good example is the work of Frémont (2007) mapping the global port network of Maersk, the world's main liner shipping company, while it does not include reference to changes in local performance resulting from global insertion.

\subsubsection{Port regions and port systems}

Another approach wishes to situate ports within a precise port region or maritime region. Despite the lack of clarity about the definition of such terms ${ }^{4}$, these studies have in common to give more importance to the architecture of the maritime networks, where ports are only one aspect. An original insight inspired from maritime history is proposed by Westerdahl

\footnotetext{
${ }^{4}$ Ducruet (2009) differentiates the maritime façade (coastal alignment of ports), the port region (inland area smaller than the hinterland and wider than the port city where port activities influence the economic structure), the port range (coastal system of interdependent ports), the port network (portfolio distribution of a given carrier), and the port system or system of ports (interconnection of ports by shipping networks within a given area).
} 
(1996) that looks at how maritime itineraries shape functional regions in Scandinavia and Europe in the early Middle Ages. In a similar vein but based on the application of network algorithms, Joly (1999) proposed a worldwide analysis of maritime linkages among main regions, resulting in the calculation of estimated port throughputs based on vessel movements. Other specific studies of liner networks cover specific regional areas such as the North Atlantic (Helmick, 1994), the Caribbean (Veenstra et al., 2005; McCalla et al., 2005; Wilmsmeier and Hoffmann, 2008), the Mediterranean (Cisic et al., 2007), and the relative position of North Korean ports in Northeast Asia (Ducruet, 2008b). While such studies clearly focus on port performance and maritime network design, notably visualizing the situation of ports in such networks, they do not have a multi-level approach, and they rarely relate network attributes with port performance ${ }^{5}$.

Despite their fundamental legacy in clarifying our understanding of contemporary shipping and port development, two main weaknesses may be highlighted across such studies. Firstly, the regional scale in which ports are studied is often defined arbitrarily: this is an argument defended by Slack (1999) in his study on the evolution of containerisation in the North Atlantic. Therefore, the regional areas within which different ports share privileged linkages are taken for granted and are not well-known in their reality. Secondly, individual measures of port performance rarely include different levels of observation, from the local to the global, although it is recognized that contemporary ports should be better compared through their ability connecting scales rather than through their traffic volume rankings (De Roo, 1994). It seems that those objectives - definition of regional areas and individual measures - cry out for an engagement in current research on social network analysis and small worlds.

\section{STRUCTURE OF THE WORLD MARITIME SYSTEM}

\subsection{Data source and methodology}

\footnotetext{
${ }^{5}$ This statement should not ignore that some authors point at specific situations in which a relationship is established between performance and network design. For instance, Lago et al. (2001) note that last ports of call attract more cargo on average due to transit time advantage; Notteboom (2006) specifies that upstream ports generate more cargo throughputs due to their situation because ocean carriers compensate the deviation distance and time; Ducruet (2008b) measured that ports situated within larger urban regions often have a higher share of long-distance connections in their traffic. The main problem underlined in this chapter is the lack of systematic empirical verification, notably on a world scale.
} 
Three main data sources exist for the analysis of maritime networks from a graph perspective. The already mentioned Containerisation International Yearbooks offer an overview of the main service schedules of the world's shipping lines, together with the fleet capacity of the companies by vessel. Although such information would allow building the world graph of inter-port linkages, and has the advantage of a cheaper cost compared to other sources, it necessitates huge efforts of data manual encoding. Another problem is the lack of coverage on local and regional services, and the probable mismatch with effective ports of call.

Two other sources provide numeric information on effective vessel movements: the French ship broker Barry Rogliano Salles through its branch company AXS Marine that proposes the Alphaliner database on container vessel movements. The source used in this chapter is derived from Lloyd's Marine Intelligence Unit (LMIU), a service of Lloyd's, the world leader in maritime insurance and shipping information based in London. This data is selected because of the wide coverage of the world fleet $\left(98 \%\right.$ TEUs $^{6}$ in 2006), as seen in Table 1. Data also includes ship operators' names, daily ports of call (previous, current, and next), allowing many measures by link and by port.

\section{[TABLE 1]}

A fundamental reflection is necessary about the way vessel movements should be computed in order to answer issues on port performance and port regions. Several aspects deserve careful attention:

- Weight and frequency of linkages: many vessel movements of different capacities pass through the same links within a given period of time. Therefore, edges can be weighted according to the total traffic (sum of all vessel capacities), the number of vessels, the number of calls, or by ratios such as average vessel capacity, weekly average number of calls, etc. In this study we retain the total traffic realized by the overall circulation of vessels within one year time in 1996 and 2006. The same applies to vertices (ports) that can be weighted and compared based on their total capacity circulated;

\footnotetext{
${ }^{6}$ Twenty-Foot Equivalent Unit (TEU): normalized measure of container traffic and vessel capacity referring to the number of 20 -foot container boxes. Vessel capacities can also be measured in deadweight tonnage (DWT) or "commercial capacity".
} 
- Canals, straits, strategic passages: the original data contains several places that are not container ports or even seaports, such as canals (Panama, Suez), straits (Gibraltar, Dover, Dardanelles, Messina), channels (Yucatan), and other passage points at which the vessel reported a call (e.g. Tarifa and Cape Finisterre on the Iberian peninsula; Skaw in Denmark; Brixham in the UK). While such "nodes" are part of the effective movement of vessels, they do not account for port commercial operations, nor are they part of voluntarily selected logistics routes or transport chains. Because almost all pendulum services pass through Panama and Suez canals, their centrality in the graph would go beyond those of biggest commercial ports. Thus they were left out from the data ${ }^{7}$.

- Direct or indirect inter-port connections: an analysis based on direct connections would imply a simplification of the reality of shipping networks. Although direct connections provide useful insights on the way ports are related to their close neighbours, liner networks are built upon a majority of indirect calls. Line-bundling or hub-and-spoke ${ }^{8}$ are the most common services provided by ocean carriers willing to extend their influence across trading areas and continents. Thus, vessels are operated through rotating patterns that make an analysis based on indirect linkages more relevant. In addition, direct linkages may deprive some ports from their true foreland extent: a direct degree of 2 may hide an indirect degree of 30 if the port is connected to wide international logistics chains.

The methodology for building the graph consists in retrieving for each port all its direct and indirect connections through the circulation of each vessel during one year, regardless of the exact time of the connection. This enables Rotterdam to be connected with Tokyo although in reality those two ports are not connected directly by a single voyage; usual pendulum services run for three weeks between Europe and Asia through Suez Canal, including many intermediate calls. In the end, every vessel's circulation creates a complete graph in which all

\footnotetext{
${ }^{7}$ Other nodes that are commercial ports such as Istanbul (Turkey) and Port Said (Egypt) were also left out because of their enormous number of calls compared to their actual traffic. Their proximity to important strategic passages has made them reported by many vessels although not every call means a commercial operation at the terminals. Other cases include Brunsbuttel (Germany), a port at the mouth of the Elbe River, whose calls were attributed to Hamburg, the real destination. Finally, some terminals have been merged in the data with their belonged port, such as Port Botany and Sydney (Australia).

${ }^{8}$ The hub service is a combination of line-bundling with local services centralized upon one main transhipment centre. A mother vessel calls at a transhipment hub where containers can be transferred to another mother vessel (i.e. interchange) or to a feeder vessel ensuring the rest of the local or regional service (Brocard et al., 1995). There are few round-the-world (RTW) services where ships are bigger. Other services are pendulum services such as Europe-Asia, and local services such as Rotterdam-United Kingdom. Line-bundling services often connect different world regions while hub and spoke services are more intra-regional.
} 
ports are fully interconnected. The resulting world graph is thus a combination of all individual vessels' complete graphs.

\subsection{Topological characteristics and geographical structure}

The resulting graphs are characterized by a high complexity (Table 2). The high cyclomatic number, where $\mathrm{p}$ is the number of separated components, indicates a high connexity of the graph. The higher the connexity, the most accessible is a node from all other nodes. This has increased between 1996 and 2006, while it is always higher for indirect links, due to a higher density of inter-port relations. However, the lattice levels are relatively low, probably due to the hierarchical nature of the network. The global connectivity $(\gamma)$ is also low, but it is higher for indirect links for the reasons cited above. In terms of complexity level, the high values indicate for non-planar graphs a very complex pattern. Notably, the growth rate of the number of ports connected is $27 \%$, but the maritime links grew $64 \%$ on the same period, resulting in a denser network. This is probably an effect of the factors cited by De Langen et al. (2002) on the current evolution of container networks. The observed connectivity (c) has increased for direct links but has decreased for indirect links, where it is much lower. All indicates that the graph of indirect links is denser and more complex due to the richness of inter-port relations taking into account the overall circulation of vessels instead of direct inter-port links, which tend to break the continuum of shipping.

\section{[TABLE 2]}

The structure of the graph can also be approached based on the relation between the number of ports and the number of connections (i.e. maritime degree). Results showed in Figure 1 indicate that the organization of liner networks correspond to a scale-free network that is defined by a power-law distribution. Few ports dominate the network by their high number of connections, while a majority of other ports have only limited connections. Some exceptions in the figures - few ports having fewest connections - are explained by the methodology of data collection: only a dozen ports are not very well connected to the rest of the network at both years. In terms of evolution, we see that the slope of the line and the coefficient have increased from 1996 to 2006, highlighting a concentration of the network. This result probably stems from the rationalization of carrier services, notably through the implementation of hub strategies throughout the world. 


\section{[FIGURE 1]}

The spatial structure is observable through TULIP software based on ports' betweenness centrality that is the sum by port of all their positions on shortest paths. This measure is equivalent to a level of relative accessibility within the graph. Although it does not correspond to daily preoccupations of port authorities or carriers, it helps distinguishing how ports are positioned in the overall pattern of circulations on various scales. A Gem-Frick layout is applied in order to situate the most central ports in the centre and the least central ports in the periphery (Figure 2).

Results confirm that very few ports dominate the hierarchy of centrality: "European gateways" (Rotterdam, Hamburg, Antwerp, and Bremerhaven as the Northern range) and "Asian hubs" (Singapore, Hong Kong, Shanghai, and Busan as the Asian corridor). Despite the lower score of Asian hubs in general compared with the most central European ports (Rotterdam and Hamburg), we see more many Asian ports with a relatively high centrality: Port Klang (Malaysia), Jakarta and Surabaya (Indonesia), Kaohsiung (Taiwan), Shenzhen, Ningbo and Qingdao (China). Thus, the measure of betweenness centrality seems to give more advantage to hub ports on which numerous smaller ports depend. Scandinavia and the British Isles tend to depend on Rotterdam and Hamburg, while Southeast and Northeast Asia tend to depend on their respective Asian hubs. In comparison, ports that usually rank high in traffic volume such as New York or Yokohama have a limited centrality in this respect. Outside the two cores of the system, only Miami scores high, probably because of its strategic position as a hub between the Caribbean and the North Atlantic regions.

\section{[FIGURE 2]}

The geographical dimension of the system is also made apparent when looking at the position of the ports and their region of belonging. Despite the borderless crossing of multiple services and circulations allowed by indirect linkages, a strong spatial proximity characterizes the graph. The two large clusters are separated by Middle East ports and Mediterranean ports (Europe-Asia route), while other regions are logically distributed around their respective cores: Black Sea, Scandinavia, and Africa for European gateways; Asia, Pacific and the Americas for Asian hubs. Although this global snapshot of the geographical structure does not account 
for a precise distinction amongst spatial and functional proximities, it demonstrates that the organization of the world maritime system is fundamentally geographical in scope. More advanced methods of clustering allow for a better revelation of possible hidden sub-structures in the global graph.

\section{MULTILEVEL ANALYSIS OF PORT PERFORMANCE}

3.1 Comparison of ports' network attributes

Two measures are compared with the performance of container ports (Table 3). The maritime degree is the total number of connections as described earlier, here distinguished between direct and indirect numbers. The level of hub dependence corresponds to the traffic share (\% TEUs) of the biggest connection in total port traffic. It highlights to what extent a given port depends on another port for the distribution of its traffic: the more dependent, the more vulnerable in the system.

There is a close relation between direct degree and throughput in 2006: Singapore (210) and Hong Kong (193) have the largest throughput and the highest degree. Thus, larger ports are those that deploy a wider set of connections. All this indicates that in general, network attributes closely follow (or explain) traffic hierarchies. Gateway or hub functions do not necessarily influence the results. Yet, specific locational factors may do so, as seen for Guangzhou (Pearl River Delta) with a lower degree explained by a combination of upstream position - constraining the accessibility for large containerships - and proximity to the major ports of Hong Kong and Shenzhen. Traffic and degree are also very much interrelated in their evolution: their respective growth rates enjoy a coefficient $\left(\mathrm{R}^{2}\right)$ of 0.83 , with Shenzhen (China) at the top of the dynamic. We also see that ports in advanced economies tend to stabilize and rationalize (e.g. decreased degree) their position in the network, while ports in developing and emerging economies see their position improving very fast through catchingup.

[TABLE 3]

Indirect connections show a somewhat distinct pattern than the one of direct connections. Singapore (591), Hong Kong (612) and Shanghai (569) have much less worldwide 
connections than Shenzhen (1,224). This measure is thus better related with the actual foreland (i.e. commercial relations) of the port. Shenzhen is known as the world's factory, which has welcomed direct calls from global shipping lines since 1998 onwards (Wang, 1998). Here, gateway and hub functions create noticeable discrepancies along the hierarchy. For instance, European gateway ports such as Hamburg, Rotterdam, Antwerp, and Felixstowe all enjoy wider global connections than ports of equivalent throughput. Gateway ports are more likely to drain vast hinterlands and thus to connect a diversity of overseas markets. Hub ports have a simplified foreland in comparison because of narrowed hinterlands. The relation between the respective growth rates of traffic and indirect degree remains quite significant with a coefficient $\left(\mathrm{R}^{2}\right)$ of 0.74 .

In terms of hub dependence, the direct vulnerability of some ports despite their large throughput is made evident. The traffic share of one direct link reveals a higher vulnerability for Shenzhen (50\%), Kaohsiung (31\%), Guangzhou (41\%), Xingang (32\%), Laem Chabang (30\%), Xiamen (35\%), and Jeddah (43\%). This is because many Asian ports depend on another hub for accessing the rest of the system, but the case of Kaohsiung is highly political with the obligation connecting Hong Kong instead of mainland Chinese ports across the straits. Hub ports and gateway ports have a more evenly spread of traffic connections, as seen with New York (15\%) and Busan (13\%). European gateway ports have intermediate values around $25 \%$ due to the existence of port systems such as the North European range fro Le Havre to Hamburg. Local strategies of port development also greatly impact the level of hub dependence. Important drop for Port Klang (-35\%) clearly reflects a successful relief from the dominance of neighbouring Singapore, following Malaysian government support for gateway development. In comparison, Shenzhen and Guangzhou could not much decrease their dependence upon the Hong Kong hub, nor could Ningbo reduce its dependence upon Shanghai.

Again for indirect hub dependence, the highest values in 2006 are for Asian ports, due to unavoidable concentration of circulation at a neighbouring hub, such as Kaohsiung (14\%) with Hong Kong, Port Klang (15\%) and Laem Chabang (14\%) with Singapore. Continental gateways such as New York and Antwerp have the lowest hub dependence - around 5\% - for the reasons cited above, but also some Western interregional hubs such as Algeciras. Due to the comparatively limited importance of hinterlands in Asia, more interactions among Asian ports tend to increase their reciprocal interdependency and connectivity. Western ports 
function more as gateways linking hinterland with foreland, with less inter-port corridors. Thus, the indirect hub dependence can be seen as an indicator of logistics chain diversity through the importance of hinterland coverage.

\subsection{The clustering of port regions}

In this part of the analysis we use the method of strength clustering in order to highlight possible "small worlds" in the graph. However, there are inherent limitations of using such methods due to the fact that the maritime global network is a scale-free network and not a small-world network. Small worlds or "communities" - here port regions - exist less in scalefree networks due to their very hierarchical dimension: every node is in some way dominated by a "star" or "hub", making difficult the formation of relatively independent groups of ports enjoying preferential relations. We apply strength clustering on both the structure of the network itself (links without weight) and on the weighted graph (weight in TEUs i.e. sum of circulated capacities) in order to verify the impact of traffic volume on small world formation. Such analysis shall help answering two sets of questions:

- Multilevel maritime regions: what are the tributary areas of the world's largest ports? Are they regionally specialized? What is the respective role of geographical proximity and carrier decisions to re-route their services based on economic factors (time and cost)? Are there resilient historical trade patterns still visible?

- Multilevel maritime dynamics: how do such strongly interconnected groups of ports evolve over time, given the fact that carrier strategies and port competition have profoundly modified the structure of shipping networks in the 1990s?

In 1996, there is some correspondence between the results from weighted analysis and nonweighted analysis. For instance, Hamburg appears as a key node in each analysis, although the two clusters are different by the number of ports contained and by the location of these ports. In the non-weighted cluster, Hamburg and Rotterdam stand out as the two most central ports of a dominantly European cluster (Scandinavia, South Europe), while only Belawan and Jakarta (Indonesia) are included from outside Europe. In the weighted cluster, Hamburg has also a dominance of European counterparts (Iberian Peninsula, North) of which many are in common with the non-weighted cluster, including Jakarta. Some important ports that were not 
included in the non-weighted cluster are Port Klang (Malaysia) and Keelung (Taiwan). Thus, it can be argued that weighted clusters underline important corridors on a world level (Europe-Asia) while non-weighted clusters are better related with the neighbouring architecture of a port's network (Europe).

Conversely, the geographical affinity of some central ports does not much change from nonweighted to weighted clusters. Amsterdam (with Ymuiden) is the centre of a non-weighted cluster with a majority of Latin American ports and two Australian ports. It also appears in a weighted cluster alongside with many Latin American ports, although in a less central position, due to the inclusion of large gateways such as Santos (Brazil) and Buenos Aires, and some Oceania ports (e.g. Fremantle, Auckland). Therefore, taking into account the weight of the links does not necessarily disturb the pattern. However, some very central ports such as Nagoya (Japan) and Southampton (UK), which have a strong position in some non-weighted clusters, are not part of any weighted cluster, probably due to their lower weight in the network. In addition, some very central ports in some clusters have in reality a relatively low rank in usual port rankings: Dakar (Senegal), Damietta (Egypt), Szczecin (Poland), while others are precisely strategic places for carriers to develop gateway strategies, such as Hampton Roads in the US (Starr, 1994).

In 2006, all clusters show a somewhat stronger geographical coherence than in 1996. For instance, the non-weighted cluster centred upon Antwerp includes some major European gateways (e.g. Rotterdam, Hamburg) together with a series of Latin American ports, what highlights the importance of maintained transatlantic ties. It is also the case of the nonweighted cluster centred upon La Guaira (Venezuela) linking Western Europe (Genoa, Liverpool) with North Africa (Morocco) and several Latin American ports. The two other non-weighted clusters also reveal interesting patterns. The one centred upon the rapidly growing Black Sea port of Constantza (Romania) is mostly intraregional as it concentrates mostly other North or South European ports. Conversely, the cluster centred upon Ashdod (Israel) is more diverse geographically but one can notice a spatial continuity from Southeast Asia (Bangkok) to Brazil (Rio Grande, Itajai) across Middle East, Mediterranean, and North African ports. Only a few exceptions deviate from this corridor of ports.

[FIGURE 3]

[FIGURE 4] 
What becomes clear with weighted clusters is the very important role of geographical and historical continuum. A Northeast Asian cluster centred upon Yokohama interestingly connects some outer ports; a "Latin" cluster centred upon Cartagena (Colombia) primarily gathers South European and Latin American ports; another cluster centred upon Antwerp is dominantly European with some US Gulf Coast ports; and finally a cluster centred upon Dakar with a mix of African and Asian ports ${ }^{9}$. The evolution between 1996 and 2006 for weighted clusters shows some permanency, with a majority of Iberian Peninsula / Latin American / Northeast Asia / European ports differently represented within a few central clusters.

\section{CONCLUSION}

This chapter has for the first time applied a multilevel analysis to maritime transport and, in particular, to liner shipping networks formed by the daily circulation of container vessels on a world level. What can be learned from such attempt? First, we confirm that liner shipping is characterized by high complexity, while the network properties of seaports interestingly are in line with usual port hierarchies provided by economic intelligence and earlier academic studies on port performance. Second, the clustering methodology applied to the world graph of direct and indirect inter-port links, with or without traffic, provides rather unusual combinations of ports that do not correspond to our vision of the world delimitated by political and cultural criteria.

Thus, retrieving the inherent functional, spatial, economic - and perhaps accidental - logic of each cluster would necessitate enormous efforts of data checking from the raw dataset itself. What should port specialists understand from the results? Some clusters are not easy to "define" since they also do not exactly overlap with usually defined geographical areas or systems in port geography, such as port ranges and hub port regions. For instance, Yokohama appears as the most central port in a Northeast Asian cluster whereas all indicates in the literature that Busan (South Korea) has the strongest position in this region as a hub. This is perhaps where the methodology goes in a somewhat different direction than the literature

\footnotetext{
${ }^{9}$ Numerous smaller weighted or non-weighted clusters often appear in the Scandinavian region, Oceania, and Northeast Asia where there is a high density of small ports enjoying many links with each other. They do not appear in the figures for better clarity.
} 
mainstream: hub ports (i.e. stars) where many links converge have a relatively lesser importance in the results because instead of forming - or belonging to - small worlds, they tend to create hierarchy and polarity in the system.

There are very positive lessons to learn however from the application of such methods to liner shipping, for port and maritime geography. Despite the "automatic" dimension of clustering, strong coherence is to be found in a number of clusters where either geographical or commercial/cultural logics dominate, as seen with transatlantic groupings or South-South groupings. Surprisingly, we did not find many clusters including the biggest ports of the Triade altogether as dominant poles of a world system (e.g. North America, Western Europe, and East Asia). It means that the world maritime system is regionally polarized but not globally polarized: some corridors link different regions through a complex mix of pendulum, round-the-world, and other line-bundling services while intraregional services tend to be the most concentrated upon a few ports. This confirms that liner shipping does not exactly overlap with trade routes: hub strategies of global ocean carriers have rerouted dominant flows towards many hub ports in the Caribbean, the Mediterranean, and Asia as a whole, for the aforementioned reasons. Perhaps, further research focusing more on finding a better match between the world economic system and the world maritime system should "delete" such hub ports from the map? The question thus is: which ports are more hubs than others? Unfortunately, the answer or methodology to answer is not yet available in the literature.

Further research shall go towards several key directions to improve the analysis. First, selecting only a size category of vessels would allow refining the results: vessels over 2,000 TEUs often operate on longer-distance services (e.g. pendulum, round-the-word), while lighter vessels tend to operate on intraregional services (e.g. barging, feeder). The present analysis has mixed altogether different sizes of vessels, what in the end may have blurred the geographical logic behind vessel movements. Second, because liner shipping is operated as a scale-free network - should it be analyzed either through direct or indirect linkages - it would be interesting to make use of other types of vessels carrying commodities such as bulks or general cargo, for which hub-and-spoke strategies do not apply. Therefore, bulk and general cargo shipping tend to better overlap with trade routes and commercial patterns. Third, excluding hub ports from the analysis as mentioned above would allow a better appreciation of the trade continuum among ports of the world, and possibly provide better results in terms of clustering and small world analysis. 


\section{REFERENCES}

Bichou, K. and Gray, R. (2005) A critical review of conventional terminology for classifying seaports, Transportation Research Part A: Policy and Practice, 39(1), 75-92.

Bird, J. (1969) Traffic flows to and from British seaports, Geography, 54, 284-301.

Bird, J. (1970) Seaports are not aberrant cases, Area, 4, 65-68.

Bird, J. (1984) Seaport development: some questions of scale, in: Hoyle, B.S., Hilling, D. (Eds), Seaport Systems and Spatial Change, Chichester: Wiley, pp. 21-41.

Britton, J.N.H. (1965) Coastwise external relations of the ports of Victoria, The Australian Geographer, 9, 269-281.

Brocard, M., Joly, O. and Steck, B. (1995) Les réseaux de circulation maritime, Mappemonde, 37(1), http://mgm.fr/PUB/Mappemonde/M195/NAVIRES.pdf

Cisic, D., Komadina, P. and Hlaca, B. (2007) Network analysis applied to Mediterranean liner transport system, Paper presented at the International Association of Maritime Economists Conference, Athens, Greece, July 4-6.

Clark, X., Dollar, D. and Micco, A. (2004) Port efficiency, maritime transport costs, and bilateral trade, Journal of Development Economics, 75(2), 417-450.

De Langen, P.W., Van der Lugt, L.M. and Eenhuizen, J.H.A. (2002) A stylised container port hierarchy: a theoretical and empirical exploration, Paper presented at the International Association of Maritime Economists Conference, Panama, November 13-15.

Ducruet, C. (2008a) World typology of port-city relationships, Cybergeo, 417, http://www.cybergeo.eu/index17332.html

Ducruet, C. (2008b) Hub dependence in constrained economies: the case of North Korea, Maritime Policy and Management, 35(4), 374-388.

Ducruet C., Roussin, S. and Jo J.C. (2009) Going West? Spatial polarization of the North Korean port system, Journal of Transport Geography (forthcoming).

Ducruet C. and Van Der Horst, M.R. (2009) Transport integration at European ports: measuring the role and position of intermediaries, European Journal of Transport Infrastructure Research (forthcoming).

Fleming, D.K. (2000) A geographical perspective of the transhipment function, International Journal of Maritime Economics, 2(3), 163-176.

Fleming, D.K. and Hayuth, Y. (1994) Spatial characteristics of transportation hubs: centrality and intermediacy, Journal of Transport Geography, 2(1), 3-18.

Frémont, A. (2005) Conteneurisation et mondialisation. Les logiques des armements de lignes régulières, Texte d'Habilitation à Diriger les Recherches, Université Paris I Sorbonne, Paris.

Frémont, A. (2007) Global maritime networks: the case of Maersk, Journal of Transport Geography, 15(6), 431-442.

Frémont, A. and Soppé, M. (2005) Transport maritime conteneurisé et mondialisation, Annales de Géographie, 642, 187-200. 
Helmick, J.S. (1994) Concentration and Connectivity in the North Atlantic Liner Port Network, 1970-1990, Miami: University of Miami.

Joly, O. (1999) La Structuration des Réseaux de Circulation Maritime, Unpublished PhD dissertation in Territorial Planning, Le Havre: Le Havre University.

Lee, S.W., Song, D.W. and Ducruet, C. (2008) A tale of Asia's world ports: the spatial evolution in global hub port cities, Geoforum, 39(1), 372-395.

McCalla, R., Slack, B. and Comtois, C. (2005) The Caribbean basin: adjusting to global trends in containerization, Maritime Policy and Management, 32(3), 245-261.

Notteboom, T.E. (2006) Traffic inequality in seaport systems revisited, Journal of Transport Geography, 14(2), 95-108.

Notteboom, T.E. and Rodrigue, J.P. (2005) Port regionalization: towards a new phase in port development, Maritime Policy and Management, 32(3), 297-313.

Olivier, D. and Slack, B. (2006) Rethinking the port, Environment and Planning A, 38(8), 1409-1427.

Robinson, R. (2002) Ports as elements in value-driven chain systems: the new paradigm, Maritime Policy and Management, 29(3), 241-255.

Slack, B. (1985) Containerization, inter-port competition, and port selection, Maritime Policy and Management, 12(4), 293-303.

Slack, B. (1993) Pawns in the game: ports in a global transportation system, Growth and Change, 24(4), 579-588.

Slack, B. (1999) Satellite terminals: a local solution to hub congestion?, Journal of Transport Geography, 7(4), 241-246.

Slack, B. and Frémont, A. (2005) Transformation of port terminal operations: from the local to the global, Transport Reviews, 25(1), 117-130.

Slack, B. (2007) The terminalization of ports: an academic question? Paper presented at the International Workshop on New Generation Port Cities and their Insertion in Global Supply Chains, Hong Kong, December 12-14.

Starr, J.T. (1994) The mid-Atlantic load centre: Baltimore or Hampton Roads?, Maritime Policy and Management, 21(3), 219-227.

Veenstra, A.W., Mulder, H.M. and Sels, R.A. (2005) Analysing container flows in the Caribbean, Journal of Transport Geography, 13(4), 295-305.

Vigarié, A. (1995) La Mer et la Géostratégie des Nations, Paris: Economica \& Institut de Stratégie Comparée.

Von Schirach-Szmigiel, C. (1973) Trading areas of the United Kingdom ports, Geografiska Annaler, 55B, 71-82.

Westerdahl, C. (1996) Traditional zones of transport geography in relation to vessel types, Internet Document: http://www.abc.se/ pa/publ/transport.htm

Wilmsmeier, G. and Hoffmann, J. (2008) Liner shipping connectivity and port infrastructure as determinants of freight rates in the Caribbean, Maritime Economics and Logistics, 10(1-2), 130-151. 
Table 1: Overview of the maritime database

\begin{tabular}{|l|r|r|}
\hline & \multicolumn{1}{|c|}{1996} & \multicolumn{1}{|c|}{$\mathbf{2 0 0 6}$} \\
\hline No. Ports & 975 & 1,240 \\
No. Countries & 157 & 173 \\
No. Vessel movements & 176,439 & 390,740 \\
No. Vessels & 1,759 & 3,973 \\
No. Operators & 497 & 720 \\
Total slot capacity (TEUs) & $3,352,849$ & $9,590,309$ \\
Total deadweight capacity (DWTs) & $50,644,151$ & $130,742,023$ \\
\hline Share world fleet (\% containerships) & 91.52 & 98.33 \\
Share world fleet (\% TEUs) & 92.15 & 97.91 \\
Share world fleet (\% DWTs) & 6.23 & 12.54 \\
\hline
\end{tabular}

Source: calculated by authors based on LMIU and UNCTAD

Table 2: Topological characteristics of the world maritime network, 1996-2006

\begin{tabular}{|c|c|c|c|c|c|c|c|}
\hline \multirow{2}{*}{\multicolumn{2}{|c|}{ Measure }} & \multirow{2}{*}{ Description } & \multirow{2}{*}{ Calculation } & \multicolumn{2}{|c|}{ Direct links } & \multicolumn{2}{|c|}{ Indirect links } \\
\hline & & & & 1996 & 2006 & 1996 & 2006 \\
\hline $\mathrm{e}$ & Length & Number of edges & Sum & 6,322 & 9,493 & 29,251 & 51,054 \\
\hline $\mathrm{V}$ & Population & Number of vertexes & Sum & 975 & 1,240 & 975 & 1,240 \\
\hline k & $\begin{array}{l}\text { Cyclomatic } \\
\text { number }\end{array}$ & $\begin{array}{l}\text { Number of } \\
\text { independent cycles }\end{array}$ & $e-v+p$ & 5,347 & 8,253 & 28,676 & 49,814 \\
\hline$a$ & Alpha & Lattice degree & $\mathrm{k} /((\mathrm{v}-1) *(\mathrm{v}-2) / 2)$ & 0.011 & 0.010 & 0.011 & 0.010 \\
\hline$\beta$ & Beta & $\begin{array}{l}\text { Degree of graph } \\
\text { complexity }\end{array}$ & $\mathrm{e} / \mathrm{v}$ & 6.484 & 7.655 & 30.001 & 41.172 \\
\hline y & Gamma & Global connectivity & $e /\left(v^{*}(v-1) / 2\right)$ & 0.013 & 0.012 & 0.061 & 0.066 \\
\hline C & $\begin{array}{l}\text { Connectivity } \\
\text { degree }\end{array}$ & $\begin{array}{l}\text { Observed vs. optimal } \\
\text { connectivity }\end{array}$ & $\left(v^{*}(v-1) / 2\right) / e$ & 75.106 & 80.920 & 16.232 & 15.046 \\
\hline
\end{tabular}

Source: calculated by author based on LMIU and Joly (1999) 
Table 3: Throughput volumes and network attributes of the world's 30 main container ports

\begin{tabular}{|c|c|c|c|c|c|c|c|c|c|c|c|}
\hline \multirow{3}{*}{ 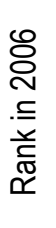 } & \multirow[t]{3}{*}{ Port } & \multicolumn{2}{|c|}{$\begin{array}{l}\text { Container } \\
\text { throughput } \\
\text { (000s TEU) }\end{array}$} & \multicolumn{4}{|c|}{ Maritime degree } & \multicolumn{4}{|c|}{ Hub dependence ( $\%$ TEU) } \\
\hline & & \multirow{2}{*}{2006} & \multirow{2}{*}{1996} & \multicolumn{2}{|c|}{ Indirect links } & \multicolumn{2}{|c|}{ Direct links } & \multicolumn{2}{|c|}{ Indirect links } & \multicolumn{2}{|c|}{ Direct links } \\
\hline & & & & 2006 & 1996 & 2006 & 1996 & 2006 & 1996 & 2006 & 1996 \\
\hline 1 & Singapore & 24,792 & 12,943 & 591 & 439 & 210 & 154 & 11.5 & 6.5 & 21.1 & 32.3 \\
\hline 2 & Hong Kong & 23,230 & 13,460 & 612 & 407 & 193 & 132 & 8.0 & 5.7 & 15.6 & 30.5 \\
\hline 3 & Shanghai & 1,710 & 1,930 & 569 & 235 & 185 & 63 & 9.9 & 7.4 & 18.3 & 33.5 \\
\hline 4 & Shenzhen & 18,468 & 1,032 & 1,224 & 103 & 177 & 30 & 6.8 & 6.3 & 0.0 & 52.5 \\
\hline 5 & Busan & 12,030 & 4,725 & 502 & 328 & 180 & 110 & 8.8 & 6.7 & 13.4 & 19.7 \\
\hline 6 & Kaohsiung & 9,774 & 5,063 & 456 & 294 & 127 & 90 & 13.9 & 7.1 & 31.2 & 40.9 \\
\hline 7 & Rotterdam & 9,690 & 4,935 & 622 & 433 & 145 & 137 & 5.4 & 5.1 & 24.3 & 20.3 \\
\hline 8 & Dubai & 8,923 & 2,247 & 394 & 233 & 143 & 55 & 8.8 & 4.9 & 17.3 & 18.3 \\
\hline 9 & Hamburg & 61 & 3,054 & 87 & 443 & 123 & 117 & 8.1 & 6.6 & $?$ & 27.7 \\
\hline 10 & Los Angele & 69 & 2,682 & 28 & 241 & 56 & 63 & 8. & 6.7 & 25.6 & 33.4 \\
\hline 11 & Qingdao & 7,702 & 810 & 445 & 142 & 100 & 28 & 8.6 & 6.6 & 22.6 & 30.1 \\
\hline 12 & Long Beach & 7,290 & 3,007 & 317 & - & 46 & - & 10.5 & - & 27.1 & . \\
\hline 13 & Ningbo & 7,068 & - & 434 & 70 & 101 & 14 & 11.0 & 8.7 & 32.0 & 34.4 \\
\hline 14 & Antwerp & 7,018 & 2,653 & 548 & 416 & 96 & 101 & 5.0 & 4.8 & 32.3 & 18.6 \\
\hline 15 & Guangzhou & 600 & 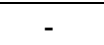 & 236 & 50 & 31 & 14 & 13.0 & 8.6 & 41.2 & 53.8 \\
\hline 16 & Port Klang & 320 & 1,409 & 47 & 264 & 134 & 54 & 15. & 7.1 & 27 & 62.4 \\
\hline 17 & Xingang & 5,900 & 800 & 3 & 151 & 54 & 42 & 12.6 & 6.9 & 31.9 & 28.3 \\
\hline 18 & New York & 5,092 & 2,269 & 324 & 300 & 75 & 63 & 4.6 & 4.5 & 15.3 & 28.1 \\
\hline 19 & Tanjung Pelepas & 4,770 & - & 340 & - & 74 & & 8.6 & - & 16.1 & - \\
\hline 20 & Bremerhaven & 4,450 & 1,543 & 433 & 324 & 92 & 57 & 10.1 & 6.2 & 22.4 & 34.9 \\
\hline 21 & Laem Chabang & 4,123 & 820 & 313 & 166 & 60 & 25 & 14.2 & 7.2 & 29.9 & 34.1 \\
\hline 22 & Xiamen & 4,019 & 400 & 392 & 86 & 74 & 20 & 15.0 & 7.0 & 35.2 & 36.9 \\
\hline 23 & Tokyo & 3,665 & 2,311 & 330 & 208 & 74 & 51 & 9.3 & 7.3 & 18.7 & 14.9 \\
\hline 24 & Jawaharlal I & 3,298 & 423 & 343 & 149 & 50 & 20 & 10.3 & 4.4 & 16.7 & 23.5 \\
\hline 25 & Algeciras & 3,245 & 1,307 & 370 & 247 & 104 & 62 & 4.6 & 5.0 & 28.7 & 40.5 \\
\hline 26 & Dalian & 3,212 & - & 340 & 113 & 69 & 24 & 9.0 & 6.4 & 24.0 & 19.5 \\
\hline 27 & Yokohama & 3,200 & 2,334 & 389 & 318 & 100 & 86 & 10.1 & 6.5 & 17.2 & 19.5 \\
\hline 28 & Colombo & 3,079 & 1,356 & 381 & 258 & 63 & 51 & 9.3 & 5.8 & 20.3 & 40.2 \\
\hline 29 & Felixstowe & 3,000 & 2,042 & 415 & 369 & 64 & 86 & 8.0 & 6.0 & 28.0 & 21.5 \\
\hline 30 & Jeddah & 2,964 & 827 & 341 & 256 & 59 & 41 & 8.2 & 5.6 & 43.7 & 45.4 \\
\hline
\end{tabular}

Source: calculated by author based on LMIU and Containerisation International 
Figure 1: Scale-free dimension of the world maritime network, 1996-2006

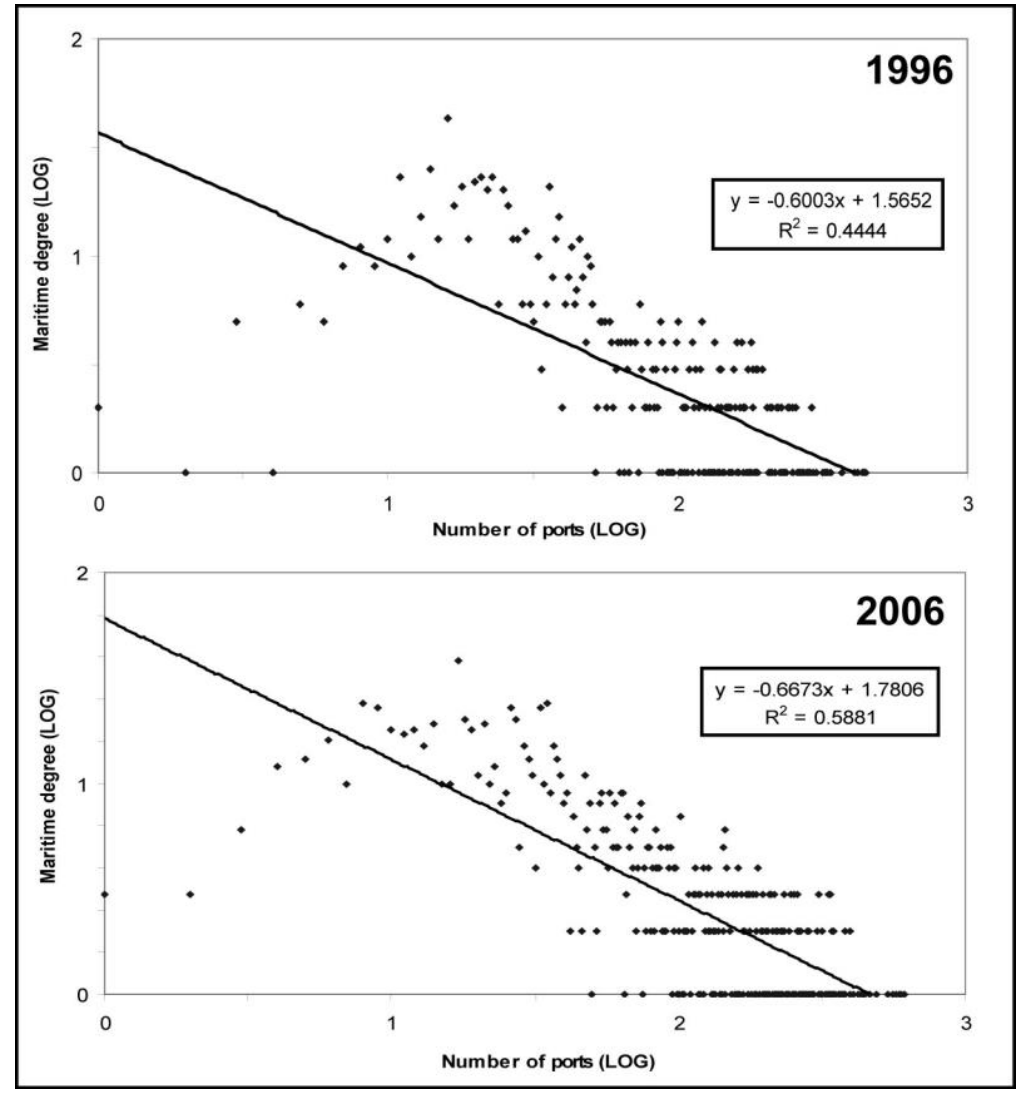

Source: calculated by author based on LMIU 
Figure 2: Visualization of the world maritime system, 2006

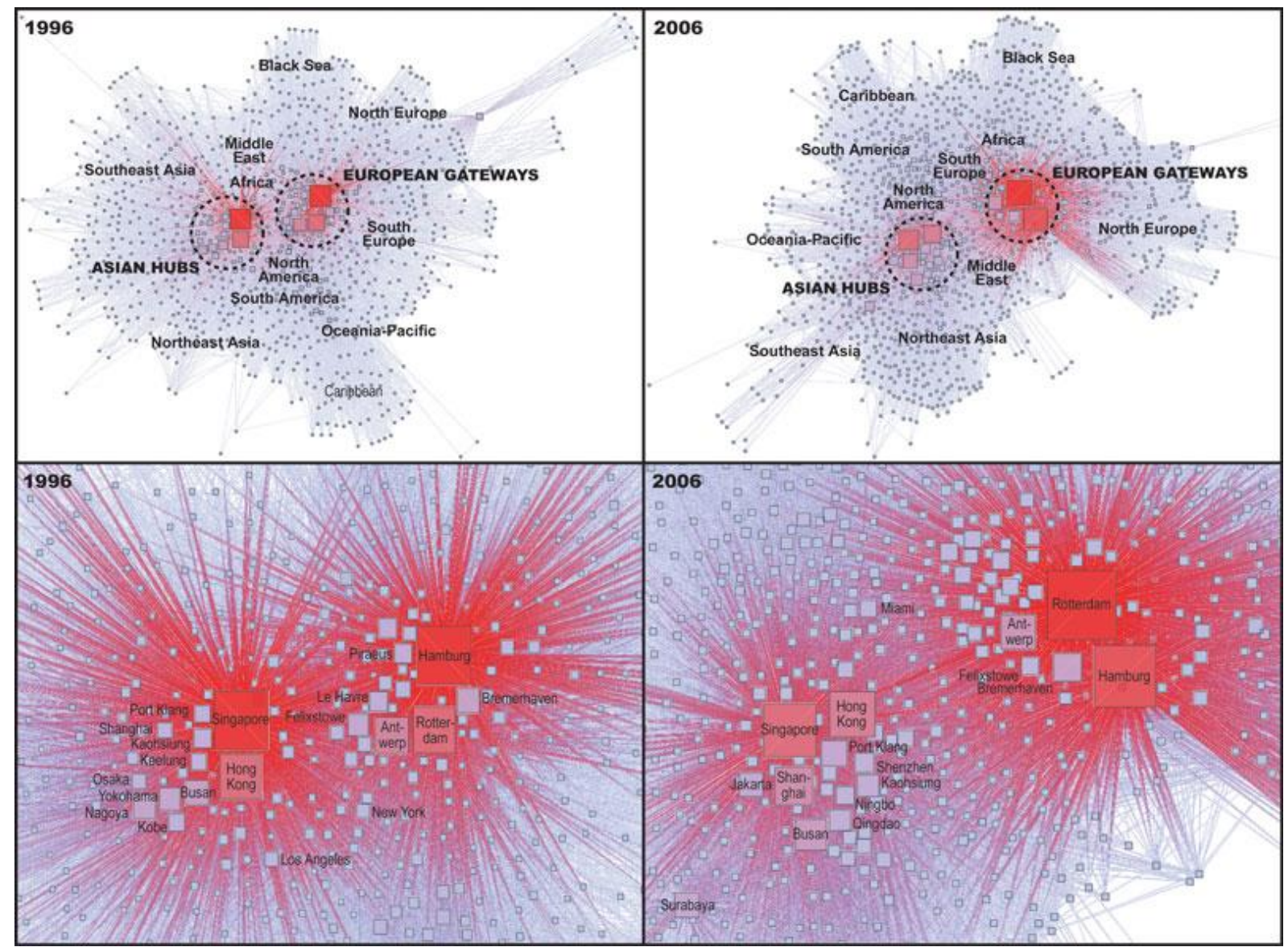

Source: realized by author based on LMIU and TULIP 
Figure 3: Central clusters in the world maritime system, 1996

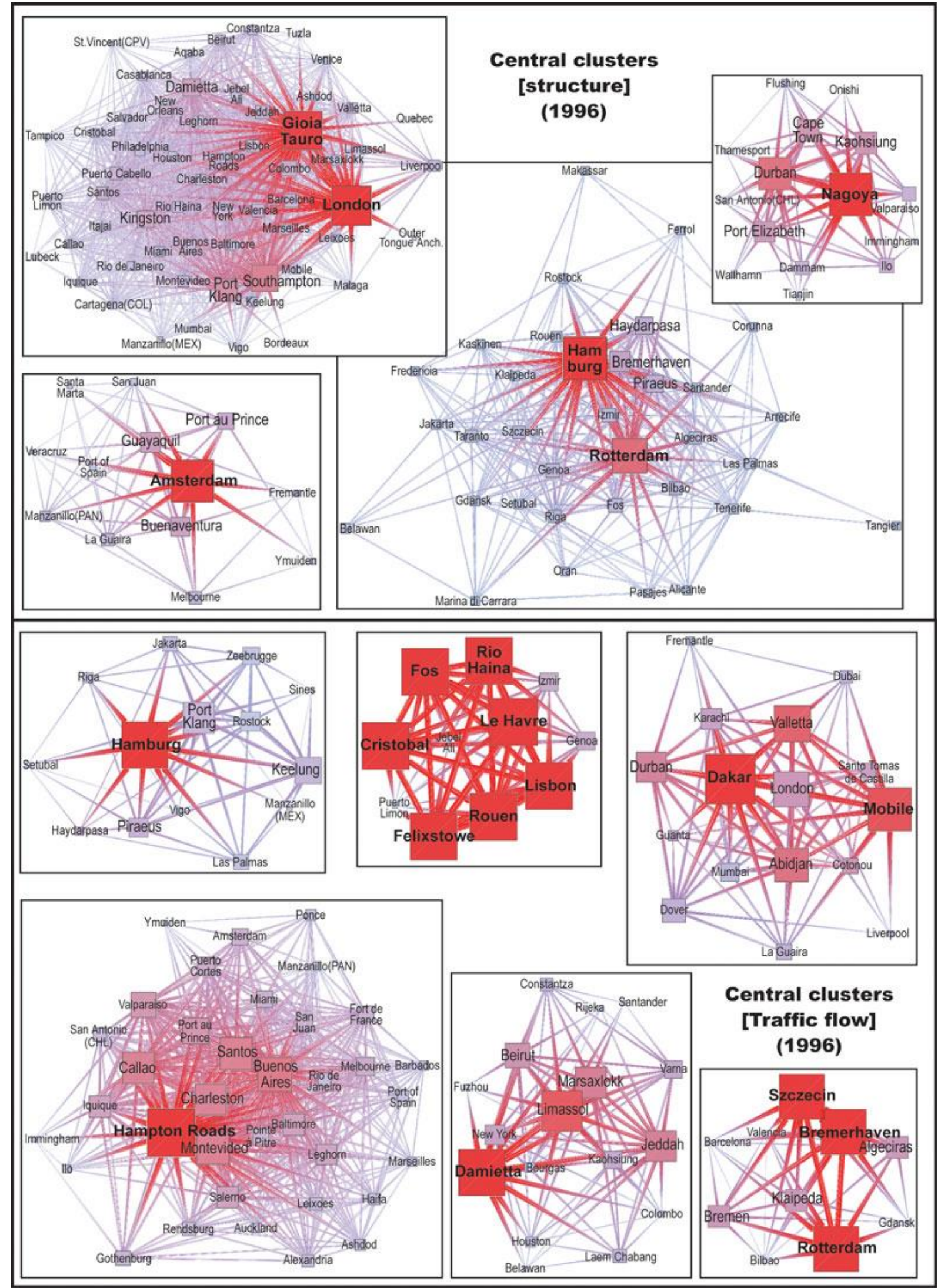

Source: realized by author based on LMIU and TULIP 
Figure 4a: Central clusters in the world maritime system, 2006

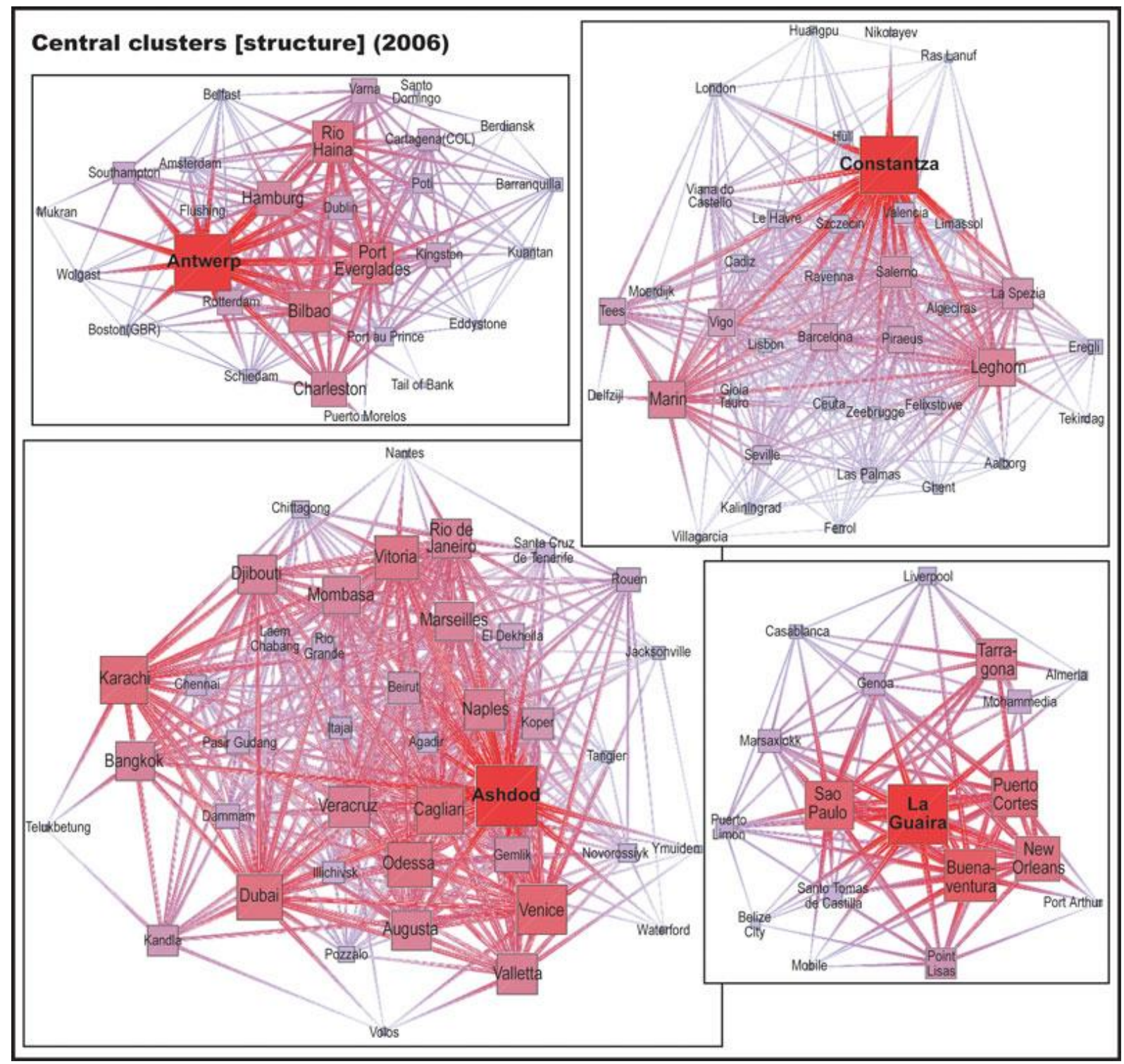

Source: realized by author based on LMIU and TULIP 
Figure 4b: Central clusters in the world maritime system, 2006 (continued)

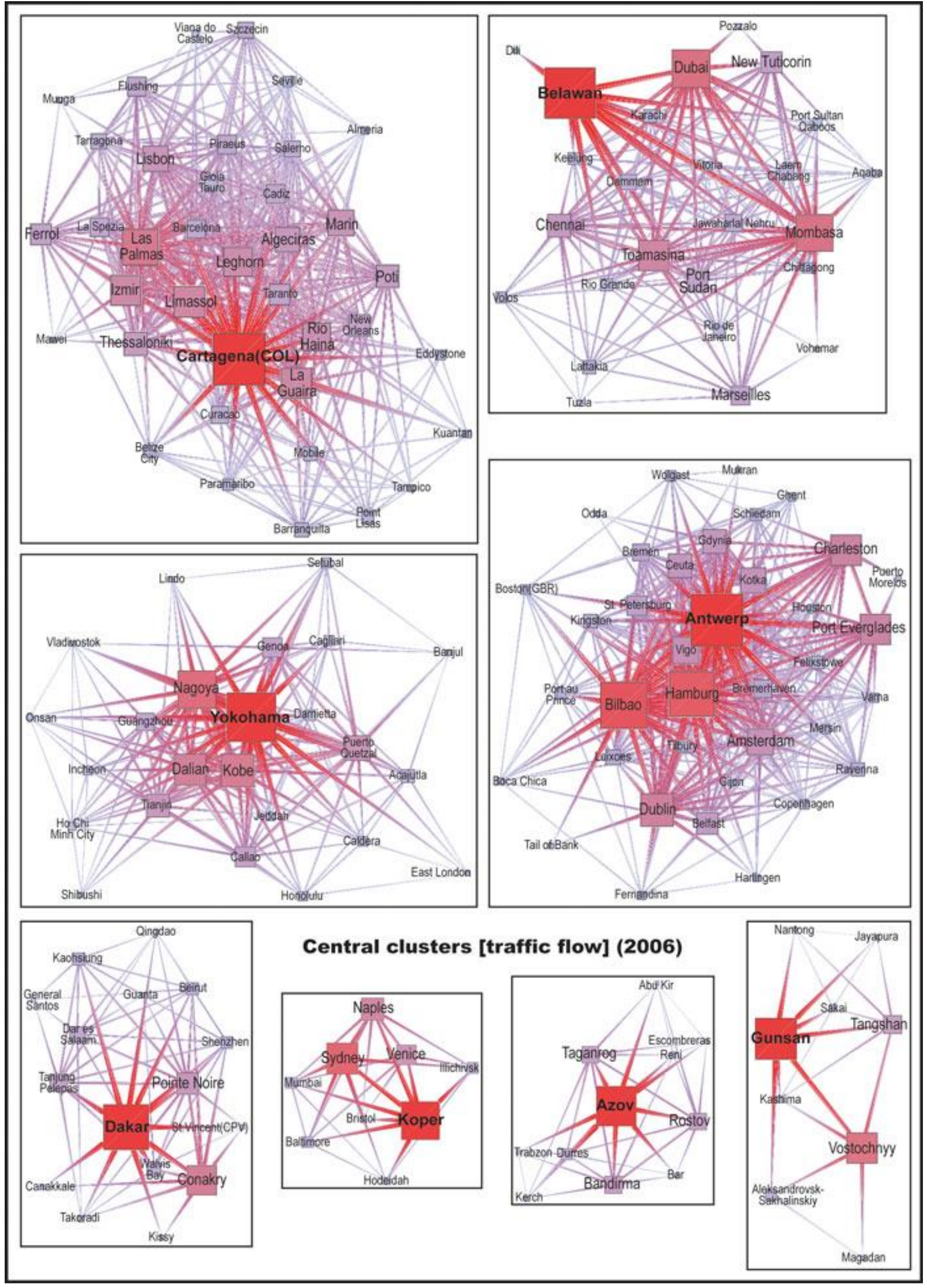

Source: realized by author based on LMIU and TULIP 